\title{
An Integrated Importance-Performance Analysis and Modified Analytic Hierarchy Process Approach to Sustainable City Assessment
}

\section{Say Wah Lee}

Shanghai Jiao Tong University https://orcid.org/0000-0001-6561-2030

KeXue ( $\square$ kxue@sjtu.edu.cn)

Shanghai Jiao Tong University

\section{Research Article}

Keywords: Importance-performance analysis (IPA), analytic hierarchy process (AHP), multiple criteria decision making (MCDM), sustainable urban development, sustainable city indicators, urban sustainability, sustainable development goals, Malaysia

Posted Date: March 10th, 2021

DOI: https://doi.org/10.21203/rs.3.rs-207767/v1

License: @ (1) This work is licensed under a Creative Commons Attribution 4.0 International License. Read Full License

Version of Record: A version of this preprint was published at Environmental Science and Pollution Research on July 5th, 2021. See the published version at https://doi.org/10.1007/s11356-021-15235-0. 


\section{Abstract}

Sustainable urban development has been a popular subject in urban studies and related disciplines. Owing to the challenges faced by cities worldwide to accommodate the growing urban populations, it is becoming ever more important for innovative research on sustainable urban development to be performed to help cities achieve sustainability. This study develops and tests an integrated approach to sustainable city assessment, which is a combination of importance-performance analysis (IPA) and modified analytic hierarchy process (AHP). Questionnaires designed following the IPA concept were distributed to residents of three cities. The importance scores from the collected data were factorized and the relative scores of the factors were then converted into pairwise comparisons using a formula developed in this study. The derived criteria weights were applied to the performance scores to evaluate the cities' relative overall sustainability performance. This approach replaces the AHP's 1-9 scale with the IPA's importance rating scale, which is a Likert scale, in the questionnaire. Based on the findings, implications and future research suggestions were provided.

\section{Introduction}

In 2015, the United Nations (UN) introduced the 2030 Agenda for Sustainable Development which consists of 17 Sustainable Development Goals (SDGs) and 169 targets to build on the previous Millennium Development Goals and to promote global sustainable development (UN 2015). Sustainable development is defined as "development that meets the needs of the present without compromising the ability of future generations to meet their own needs" (UN 1987). The SDGs guide nations to achieve sustainability through integrated and balanced developments in the economic, social, and environmental dimensions. Goal 11 of the SDGs titled "Make cities and human settlements inclusive, safe, resilient and sustainable," which concerns sustainability issues in human settlements as a result of urbanization, has propelled over 150 countries to develop national policies for sustainable urban development (UN 2018b).

More than half of the global population is living in the cities today and the proportion is expected to increase to $68 \%$ by the year 2050 (UN 2018a). As highlighted in the UN's (2017) New Urban Agenda, economic, social, cultural, and environmental impacts are intensifying in cities due to the growing urban populations. Therefore, efforts to ensure sustainable urban growth have to be enhanced to safeguard the well-being of urban residents and habitats both in the present and in the future. Urban residents should have access to safe living conditions, affordable housing, sufficient public infrastructure and facilities, clean air and water, and other basic needs to live comfortably in the city. The UN's slogan for the New Urban Agenda, "Cities 2030, cities for all," signifies that by the year 2030, cities should be environmentally, socially, economically, and culturally sustainable and inclusive with equal benefits and opportunities for all inhabitants, including the present and future generations, to live in sustainable environments and contribute toward the quality of life of all (UN-Habitat 2017).

The differences between cities in terms of landscape, finance, culture, infrastructure, and others require cities to have customized approaches to sustainable development to suit their needs and conditions (Macke et al. 2018). Using multiple criteria decision making (MCDM) techniques, the perceived performances of cities based on various criteria of sustainable development can be measured to facilitate decision making tailored to the cities' development needs. MCDM methods have often been applied in research related to sustainable development (Mardani et al. 2015). The analytic hierarchy process (AHP) by Saaty (1980) is a popular MCDM technique that has been employed in numerous urban sustainability research (e.g., Bunruamkaew \& Murayam 2011; Ma et al. 2020; Youssef et al. 2011; Zhang et al. 2012). Importance-performance analysis (IPA), a method to measure the importance and performance of attributes, has been combined with the AHP for analysis in several urban development studies (e.g., Akbar et al. 2018; Lirn et al. 2012; López et al. 2019), among other disciplines. However, none has modified the AHP's 1-9 scale to suit the IPA's importance rating scale.

This research develops and tests an integrated, IPA and modified AHP approach called the IP-AHP to assess the sustainability of cities from the residents' perspectives in terms of four sustainable development dimensions: economic, social, environmental, and cultural. Using the integrated approach, questionnaires were designed according to the IPA concept and distributed to residents of three cities. From the collected data, the importance scores were first subjected to factor analysis and then the relative scores of the identified factors were converted into pairwise comparisons using a formula developed in this study. The derived criteria weights were applied to the factors' performance scores to gauge the cities' overall sustainability performances compared to each other. The Likert scale used in the questionnaire of this approach instead of the 1-9 scale makes it easier for the survey to be implemented on the general public as they could answer without the need to be trained. This can facilitate researchers to acquire a larger sample size compared to the usual, small sample size used in AHP, and fulfill the required sample size in case of high variances in expected weights (Melillo \& Pecchia 2016). Moreover, the use of a smaller scale coupled with the factorizing of subcriteria reduces the possibility of obtaining inconsistent results, which often increases as the number of measurements increases (Asadabadi et al. 2019; Bafahm \& Sun 2018). This also reduces the likelihood of the need to repeat the judgment or survey process occurring when an inconsistent result is found. Results obtained from the IP-AHP method can be discussed along with the IPA's findings on the importance and performance of the entities in terms of the criteria.

\section{Literature Review}




\subsection{Sustainable urban development assessment}

Sustainable urban development has been a popular subject for research in urban studies and related disciplines, especially in recent years (Fu \& Zhang 2017). Wang et al. (2019) performed a bibliometric analysis of over 2,500 articles on sustainable city published between 1992 and 2016 that were retrieved from the Science Citation Index Expanded and Social Science Citation Index databases, and found that the number of research on sustainable city increased exponentially between 2004 and 2016. Owing to the double-edge sword of urban growth, e.g., the rising environmental and social issues in the face of economic development, as well as the growing urban populations worldwide, countries and cities are increasingly met with challenges to accommodate the needs of urban residents (Senlier et al. 2009; UN 2018a; Wang et al. 2019). Therefore, it is becoming ever more imperative for research on sustainable urban development to be performed to help cities gauge their progress toward sustainability and implement sustainable development measures.

Many studies have established measures to assess urban sustainability, either using objective indicators (e.g., Al-Thani et al. 2018; Ma et al. 2020; Peng \& Deng 2021; Zegras et al. 2004), subjective indicators (e.g., Afacan 2015; Macke et al. 2018; Ouria 2019; Senlier et al. 2009), or both (e.g., Chan \& Lee 2019; Egger 2006; Mouratidis 2017; van Kamp et al. 2003). Objective indicators include measurements using official data, such as population density, employment rate, household income, pollution index, green area ratio, and so on, whereas subjective indicators involve perceptions or evaluations by people, such as the residents' perceived performances of their cities and their satisfaction with the cities or aspects of the cities with regards to sustainable urban development. While the objective indicators are useful for objective sustainability analysis and findings, they may not necessarily represent or project the thoughts of the people.

Urban residents' opinions should be taken into consideration in city development matters. Researchers and policy makers have stressed the importance of public participation in decision making for sustainable urban development (Afacan 2015; Musa et al. 2017; UN 2015). Urban residents have primary experiences with the cities they live in and they are among the most affected by the developments, or the lack thereof, in the cities. Therefore, their perspectives are crucial for the planning and implementation of urban policies. In Malaysia, for instance, the urban government practice a "people first" principle as they believe that in order to build sustainable cities, they must begin with the people (Federal Department of Town and Country Planning [FDTC] 2016). In Europe, the European Commission examines the quality of life in European cities every three years beginning 2004 for the purpose of urban development by surveying the cities' residents (European Commission 2016). Public perceptions about the cities they live in offer useful insights for the local authorities to identify urban problems, develop sustainability measures, and monitor their performances (Macke et al. 2018). In order for a city to develop sustainably, there should be a balanced growth in the four sustainable development dimensions, i.e., the economic, social, environmental, and cultural dimensions of the city.

\subsubsection{Economic sustainability}

Economy is a major sustainable development dimension that fuels urban growth. Urban residents' financial health indicators such as cost of living and household income are part of the economic sustainability of cities (Macke et al. 2018; van Kamp et al. 2003). Overall cost of living includes the amount of money that the urban residents have to spend on goods and services, housing, food, and other things to live in the city. Housing affordability and adequacy are among the important gauges of urban sustainability mentioned in the SDGs' Goal 11 and often studied in sustainable urban development literature and reports (Chan \& Lee 2019; Koch \& Ahmad 2018; Senlier et al. 2009). Cities should also have ample of employment opportunities enough to support the needs of the urban populations (European Commission 2016; Senlier 2009). The residents should have equal access to employment and other opportunities in the city without any form of discrimination, e.g., between different genders and ethnicities (Afacan 2015; Zegras et al. 2004). The diversity of economy, businesses, or industries in a city is also a sign of economic prosperity and sustainability (Andereck \& Nyaupane 2011; Ouria 2019)

\subsubsection{Social sustainability}

Social factors such as public facilities and services that promote the quality of life of urban residents are necessary for the sustainability of cities, for example, public transportation, recreational and sports facilities, educational facilities, and health care facilities (Chan \& Lee 2019; Macke et al. 2018; Musa et al. 2017). Good mobility and accessibility to places in the city, such as with well-connected roads and transport system, help residents to access such facilities easily (European Commission 2016; Kakar \& Khan 2020). More importantly, residents of all demographic groups, including, in particular, the elderly, women, children, and disabled people, should have the same access to the public facilities and services (Koch \& Ahmad 2018; UN 2018b). Health care facilities should be of good quality and sufficient to treat residents in need to ensure public health among the urban community, especially in times of pandemic. Other than that, there should be adequate retail sites and eateries to accommodate the residents' needs for resources daily (Howley et al. 2009; Mouratidis 2017), along with continuous supply of clean water and electricity in the city (Chan \& Lee 2019). The safety and security of residents is another important aspect of social sustainability (Afacan 2015; Ouria 2019; Senlier et al. 2009). Criminal, vandalism, and drug and alcohol abuse cases should be prevented and controlled at all times (Andereck \& Nyaupane 2011; Howley et al. 2009). Urban communities should have good relations with each other, preferably with social support networks that keep the neighbourhoods safe and healthful (Afacan 2015; Mouratidis 2017). 


\subsubsection{Environmental sustainability}

Environmental quality is another important dimension of sustainable development (Gołaś et al. 2019). Environmental pollution such as air, water, and noise pollutions are commonly-used indicators to gauge environmental sustainability in cities (European Commission 2016; Senlier et al. 2009). It is necessary for pollution levels to be tolerable by the urban inhabitants without affecting their health and daily activities. Also, there should be efficient waste management systems to ensure that solid wastes are collected regularly and minimized in the city (Chan \& Lee 2019; Hoang et al. 2019). Cities should have overall clean and tidy environments and aesthetic qualities (Afacan 2015; Mouratidis 2017). Natural environment, such as green spaces, water bodies, trees, etc., should be well preserved and sufficiently available in the city (Yilmaz et al. 2020; van Kamp et al. 2003). There should be adequate open and public spaces, whether natural or artificial, for the use of all residents. Apart from that, built environment like streets and buildings should be well maintained and resilient (European Commission 2016; Macke et al. 2018). Other important factors affecting the urban environment such as traffic congestions and crowdedness of people in the city should be also reduced and controlled (Andereck \& Nyaupane 2011; Chan \& Lee 2019).

\subsubsection{Cultural sustainability}

The preservation of cultural and historical sites, buildings, and heritage contribute to the cultural sustainability of cities (Andereck \& Nyaupane 2011; Chan \& Lee 2019; Koch \& Ahmad 2018). According to target 11.4 of the SDGs' Goal 11, efforts to conserve and protect cultural and natural heritage should be strengthened (UN 2015). Cultural facilities such as concert halls, theaters, museums, and libraries should be amply provided in the city (European Commission 2016; Macke et al. 2018; Senlier et al. 2009), along with cultural entertainments like arts, fairs, and festivals (Andereck \& Nyaupane 2011; van Kamp et al. 2003). There should also be cultural harmony and the presence of community sense of belonging among the urban residents (Afacan 2015; Musa et al. 2017).

A city's collective economic, social, environmental, and cultural performance determines its progress toward becoming a sustainable entity. Using the IP-AHP approach, cities' sustainability performance along with the levels of importance of urban sustainability indicators can be gauged through the residents' perspectives. The overall weighted performances scores of cities can be compared with each other to determine the ranking of the cities with regard to their sustainable development progress. In line with the concept of utility/welfare maximization (Varian 2014), this approach could help the local authorities to optimize the use of resources for urban development by allocating them in proportion to cities' relative overall sustainability performance, made up of weighted scores of the sustainable development dimensions, in order to improve and sustain the cities efficiently without wasting much resources.

\section{Method}

\subsection{Development of survey instrument}

To build the questionnaire for this study, relevant measurement items for the four sustainability dimensions-economic, social, environmental, and cultural-were adapted from the reviewed sustainable urban literature, such as Afacan (2015), Andereck and Nyaupane (2011), European Commission (2016), Senlier et al. (2009), and van Kamp et al. (2003). Section 1 of the questionnaire asked the respondents to rate the importance of the items to them on a 5 -point scale from $1=$ not at all important to $5=$ extremely important. Section 2 asked the respondents to rate their city of residence's performance in terms of the items on a scale of $1=$ poor to $5=$ excellent. The final section enquired the respondents' demographic.

A draft questionnaire was developed and sent to a few experts in the field for feedback, following which some adjustments were made. A pilot study was then conducted among 30 residents, 10 from each city, to examine the face validity and reliability of the measures. Sample size for the pilot study was calculated following Viechtbauer et al.'s (2015) formula at $95 \%$ confidence level and a 0.90 probability that problems would not arise in the study. Greatest lower bound to reliability (GLB) was computed on the importance scores collected from the pilot study using $R$ and a resulting value of 0.82 indicated that the measurement set was reliable. GLB was used to determine reliability as its accuracy exceeds Cronbach's alpha (McNeish 2017).

\subsection{Study areas}

Three cities in Malaysia were selected for this study, namely Kuala Lumpur, Seberang Perai, and Melaka City. Kuala Lumpur is the capital city and a federal territory of Malaysia, Seberang Perai is the largest city in Penang, a northwestern Malaysian state, and Melaka City is the capital city of Melaka, a state in southwest Malaysia. Kuala Lumpur is located in between the latter two cities. All three cities/states are situated at the west coast of Peninsular Malaysia, where most of the country's urbanization takes place. Kuala Lumpur, Penang, and Melaka are among the most densely populated, urbanized states in the country (Department of Statistics Malaysia [DOSM] 2010).

Kuala Lumpur covers an area of $243 \mathrm{~km}^{2}$ with an estimated population of 1.77 million (DOSM 2020). The city, with its 11 subdivisions, is managed by the Kuala Lumpur City Hall. Seberang Perai is one of the two parts of Penang that is situated on the mainland separated from 
Penang Island. Administered by the Seberang Perai City Council, the city consists of three districts that stretch across $751 \mathrm{~km}^{2}$ with a total population of about 840,000 recorded in the decennial census (DOSM 2010). Melaka city is a $66-\mathrm{km}^{2}$ town under the authority of the Melaka Historic City Council, which also governs other parts of Central Melaka District.

Formerly a mining city, Kuala Lumpur has progressed over the years to become one of the nation's most economically developed cities, prompting the city council to implement sustainable development measures to promote the wellbeing of residents, with efforts to provide sufficient green infrastructure in the densely populated city (Danjaji \& Ariffin 2017). The country's industrialization policy has also led to growing urbanization in Seberang Perai, which has transformed rural into urban areas, bringing about significant landscape and socioeconomic developments in the large city (Samat et al. 2014). The Melaka City, a developing city with centuries-old history, is recognized as a World Heritage by the United Nations Educational, Scientific and Cultural Organization (UNESCO) for its well-preserved, unique multicultural heritage with influences from the Malay, Portuguese, and Dutch cultures (UNESCO 2013).

\subsection{Data collection}

A cross-sectional, cluster sampling approach was used to administer the questionnaires randomly to clusters of residents in the three cities identified based on geographical regions in the map. The required sample size was calculated using confidence interval at $95 \%$ confidence level with $50 \%$ estimated variance and $5 \%$ margin of error, which gave a minimum total of 385 . About 1,000 questionnaires were distributed to residents in the three cities from 22 November to 13 December 2020 by six trained surveyors. Altogether 623 completed questionnaires were received, of which 32 were excluded due to multiple/missing responses, resulting in 591 valid for analysis with an effective response rate of $59.1 \%$.

\subsection{Data analysis}

Firstly, exploratory factor analysis (EFA) was performed on the mean importance scores using principal component analysis with promax rotation on SPSS Statistics. Next, confirmatory factor analysis (CFA) was conducted on SPSS Amos to test how well the identified factors from the EFA fit the data. The importance scores of the factors were then converted into pairwise comparisons using the following formulas:

$$
\begin{gathered}
x_{j k}=\frac{\left(a_{j}-a_{k}\right)+1}{n-2} \times 8 \\
x_{k j}=\frac{1}{x_{j k}}
\end{gathered}
$$

on the condition that $a_{j}$ is greater than $a_{k}$

where, $a_{j}$ is the importance score of the jth criterion,

$a_{k}$ is the importance score of the $k$ th criterion,

$n$ is the number of points in the Likert scale used in the study,

$x_{j k}$ is the score derived for the $j$ th criterion relative to the $k$ th criterion,

$x_{k j}$ is the score derived for the $k$ th criterion relative to the jth criterion.

The criteria being evaluated here are the factors. A simple rule of the equations is that when comparing between two criteria, the jth criterion must have a larger importance score than the $k$ th criterion, as the score of the less important criterion, $x_{k j}$, should be the inverse of the score of the more important criterion, $x_{j k}$. In the event that $a_{j}$ is equal to $a_{k}$ then $x_{j k}$ and $x_{k j}$ should each be equal to one because in AHP, criteria with the same importance levels are given the value of one. Also, $x_{j j}$ should be equal to one for all $j$. The reason one point has to be added to the difference between the importance scores in Eq. 1 is that the number one is the beginning of either side of the spectrums in a pairwise comparison scale with no absolute zero, so the difference should take into account the value of one.

The divisor in Eq. $1(n-2)$ is the range of the IP-AHP's scale. Two points have to be deducted from the Likert scale used in the study because (1) assuming a 5-point scale is used, the difference between $a_{j}$ and $a_{k}$ would be at most 4 points as respondents must select an integer from 1 to 5 for each question, and (2) further laying out the 4 points in 2 spectrums in a pairwise comparison scale with the value 1 in the middle would leave either side of the spectrums with only 3 points. The multiplier value, 8 , represents the range of the original AHP's $1-9$ scale.

The measures above should be applied to each pairwise comparison between the criteria or factors until a complete comparison matrix, $m \times m$, is established, where $m$ is the number of criteria evaluated. The succeeding steps of the AHP would follow the AHP's procedures for normalization, weight calculation, and consistency analysis. Finally, the cities' performance scores from the IPA in terms of the factors were

Page 5/14 
normalized and multiplied by the criteria weights in order to compare the overall sustainability performances between the cities. An IPA grid was plotted to illustrate the importance and performance scores by the respective cities' residents, with the grand means of the scores as crosshairs in the grid.

\section{Results}

Table 1 shows that about half of the respondents were males while the other half were females. More than a third of the respondents belonged to the 20-29 age group (37\%). Nearly half of the respondents had attained a Bachelor's degree (47.9\%). Kuala Lumpur residents constituted $40.9 \%$ of respondents, $31.3 \%$ represented Seberang Perai, and $27.8 \%$ were from Melaka City. As much as $43.5 \%$ had been in their city of residence for over 20 years.

The reliability of the measurement model, calculated using GLB, was good at 0.84 . The resulting Kaiser-Meyer-Olkin value of 0.91 and a significant Bartlett's test $(p<0.001)$ indicated that the data set was suitable for factor analysis. The EFA produced six factors from the four sustainability dimensions and each item's factor loading was above 0.50 (see Table 2). Six items, one each from the economic and cultural dimensions and two each from the social and environmental dimensions, were removed due to low factor loadings. "Economy" represented the economic dimension as a whole, "wellbeing" and "convenience" were part of the social dimension, "conservation" and "ambience" constituted the environmental dimension, and "culture" stood for the cultural dimension. Analysis from the CFA showed satisfactory fit of the model to the data with chi-square/degrees of freedom $(X 2 / \mathrm{df})=2.33$, goodness of fit index $(\mathrm{GFI})=0.94$, comparative fit index $(\mathrm{CFI})=0.95$, root mean squared error of approximation (RMSEA) $=0.05$, standardized root mean square residual $(\mathrm{SRMR})=0.05$, normed fit index $(\mathrm{NFI})=0.92$, and Tucker Lewis index $(\mathrm{TLI})=0.94$.

The correlation outcomes with measurements of average variance extracted (AVE) and composite reliability (CR) as exhibited in Table 3 showed that each factor's AVE and CR levels were above 0.50 and 0.70 , respectively, thus indicating acceptable convergent validity with the existence of internal consistency (Hair et al. 2014). The larger square root of AVE than the inter-construct correlations of each factor confirmed discriminant validity. Bivariate correlations between the factors that were all under 0.70 signified the absence of redundant factors (Tabachnick \& Fidell 2014).

Referring to Table 2, the most important factor as perceived by the residents was "wellbeing" ( $M=4.59)$, followed by "ambience" $(M=4.34)$, "economy" ( $M=4.14)$, "convenience" ( $M=4.12)$, and "conservation" $(M=4.08)$. "Culture" was rated as the least important factor $(M=3.64)$. Overall, the social dimension had the highest mean rating in importance $(M=4.35)$, followed by the environmental dimension $(M=4.21)$, economic $(M=4.14)$, and lastly, the cultural dimension $(M=3.64)$.

Using the IP-AHP calculation method described above, the importance scores were converted into pairwise comparison scores, from which the normalized weights were derived. The consistency analysis performed on the data set produced a ratio of $0.096(\leq 0.10)$ with $\lambda \max =6.60$, consistency index $=0.12$, and random index $=1.248$ (Alonso \& Lamata 2006), implying that the matrix was reliable with acceptable consistency. Table 4 exhibits the weighted performance evaluation between the three cities. The city that performed the best in urban sustainability was Melaka City (0.344), followed very closely by Seberang Perai (0.341), while Kuala Lumpur had the lowest score (0.315). The IPA grid further shows the importance and performance ratings of the cities in terms of the factors (see Fig. 1).

\section{Discussion And Conclusions}

Findings from the IP-AHP revealed that Melaka City and Seberang Perai performed better than Kuala Lumpur in sustainable urban development. Both cities are less dense compared to Kuala Lumpur, which is the densest in the nation with 7,299 persons per square $\mathrm{km}$ (DOSM 2020). Kuala Lumpur garnered the lowest performance scores for the environmental, economic, and social dimensions between the cities. Items under the environmental "ambience" factor, i.e., pollutions and traffic congestion, were among the worst rated ones by the residents of the city; all of which fell below the average point. In fact, for all cities, the overall environmental scores lied within the low-performance quadrants in the IPA grid, Q1 and Q3. Environmental issues have been some of the biggest challenges faced by cities nowadays (Al-Thani et al. 2018; Koch \& Ahmad 2018; Lee \& Xue 2020), and the Malaysian cities are no exception. With the expected ongoing urbanization in the country, the government should put more effort and investment into curbing pollutions and congestions in the cities, especially in the densely populated cities where the problems are more severe. For examples, they could enforce tighter laws to monitor and control pollutions, and implement smart technology to reduce traffic congestions.

Although the environmental "conservation" factor was found to be a low priority in this study, it is nonetheless important to conserve the natural environments of cities. Environmental impacts such as deforestation could increase carbon emissions in the city (Arshad et al. 2017). Urban green spaces, for instance, are lacking in Kuala Lumpur and Seberang Perai due to the scarcity of land (Maryanti et al. 2017; Samat et al. 2014), which could be even more so in the future as rapid developments continue. The ratio of green spaces to population in Kuala Lumpur is only 12 $\mathrm{m}^{2}$ per person, which is below the standards set by World Health Organization and Malaysia's National Urbanization Policy (FDTC 2016). 
Therefore, the conservation of existing urban green spaces along with innovative incorporation of green spaces into built environments are necessary for the cities' environmental sustainability.

Kuala Lumpur also fell short in terms of the economic dimension. In what could be the most economically-developed city of the country, the residents of Kuala Lumpur thought that the city was not economically sustainable, at least not for them. Items under the dimension such as cost of living and housing affordability were rated below the average point. The economic performances of Melaka City and Seberang Perai were not so well off either, with each scoring just above average. The citizens' slow income growth rate that does not match the inflation rate and the increase in property prices till unaffordable levels are among the major factors that contribute to high cost of living in the country (Surendran 2019). Therefore, the government have to provide adequate economic support for the lower-income residents in the cities, such as affordable home ownership schemes, subsidized goods and services, and lower barriers for economic activities. The recent declaration of federal territories in the country as temporary free trade areas is a good example of economic support for the locals (Choong 2020). Other than that, public transportation systems have to be improved to allow people to live in the suburbs, which are more affordable, and be able travel to the city centres to work with convenience. Such effort is important to help develop the suburbs as well (Shao et al. 2019).

With regard to the social dimension, Kuala Lumpur performed the worst in the "wellbeing" factor but the best in the "convenience" factor compared to the other two cities. Regardless, the social performances of all three cities fell within the high-performance quadrants in the IPA grid, Q2 and Q4, with the "wellbeing" factor being the most important of all. These imply that the cities have to keep up the good work in promoting their residents' wellbeing, such as ensuring safety and security in the city and providing quality health care and educational facilities. Although the means of "convenience" belonged to Q4, which signified possible overkill, the factor should also be taken seriously as good mobility and accessibility to places in a city is a crucial element of urban sustainability (Afacan 2015; UN 2015). Overall, the more favourable finding for the social dimension compared to the other dimensions in this study reflects the upmost focus of the Malaysian government in the urban sector, which is "people-oriented approach and community wellbeing," as reported in UN-Habitat (2017 p. iv).

As for the cultural dimension, which was the least important factor in this study, Melaka City performed better than the other two cities. Melaka City is in fact a culturally rich city that is a UNESCO World Heritage site, as described earlier. While this factor might not be that important to the residents, culture is still a necessary element of sustainable urban development (Senlier et al. 2009; UN 2015). The cultural heritage of a city or place should be conserved for the continuation of the community's long-standing identity, pride, and image (Lee \& Xue 2020). A city's vibrant culture could be a factor for tourist attraction as well, driving economic growth and cultural heritage development, as in the case of Melaka City (Teo et al. 2014). Therefore, the local authorities have to create awareness on the importance of local culture and heritage among the current generations, so that they can be preserved well for the use of the future generations.

\subsection{Contributions and implications}

Theoretically, this paper contributes to the literature by introducing a new method to integrate the IPA with modified AHP, called the IP-AHP, which measures pairwise comparisons in AHP using importance scores from the IPA. As explained above, this method does not require the use of the 1-9 scale but instead, applies measurements of the Likert scales used in IPA, making the questionnaire easier to implement on the general respondents, who can answer without being trained. Moreover, with the administration of factor analysis to statistically group the subcriteria, the use of a larger sample size that is more representative of the population, and the reduced scale in the questionnaire, the validity and consistency of the findings could be enhanced, thus minimizing the need to repeat the survey process to reach a consistent outcome. The formula derived in this study also complies with the measurement of consistency ratio in AHP. The application of the IP-AHP method in this research to assess urban sustainability for the purpose of welfare maximization further contributes to sustainable development and urban literature. This research has shown that, other than using the AHP to make decisions by way of selecting the best alternative, the method can be used to compare the relative performance of cities to facilitate decision making for optimized sustainable developments between the cities. Findings from the IP-AHP have demonstrated the ability of the urban residents to provide useful information on the importance level of the sustainable urban development indicators as well as the performance of cities based on the indicators. Beyond that, the indicators compiled in this paper can be adopted and applied in future urban development research.

On the practical side, this paper has established a method for the local authorities to measure and monitor the sustainability of cities, which can facilitate inclusive and efficient implementations of sustainable urban development initiatives. It is recommended that the residents are surveyed every now and then by the authorities to gauge their perspectives and needs over time as the cities progress. Results from the IP-AHP method could help the government to decide the proportion of resources to be allocated to the examined cities based on their relative performance. The IPA's findings could also enhance the decision making by providing further insights into the cities' performances in terms of the indicators. Since the survey is easy to be implemented on the general public, the method is suitable not only in academia, but also in organizational practices. 
Specifically, the findings of this study apply to the three examined cities in Malaysia. The analysis shows that Melaka City and Seberang Perai performed better overall compared to Kuala Lumpur, which was taught to be more polluted, congested, and costly to live in among the residents. Nevertheless, the former two cities' sustainability performance were not that well off either, as the cities' overall weighted scores and dimension scores were not far apart from each other. Also, even though the IPA ratings were categorized into quadrants of high and low, importance and performance in the grid, the importance ratings were generally within the higher range of above 4.0, whereas the ratings of the cities' performances were all below 4.0. It can be concluded that much more work has to be done by the authorities that govern the three cities in order to fulfill the needs and expectations of the residents. Further to that, developments in the cities have to be managed strategically in ways that ensure balanced growth in the sustainable development dimensions.

\subsection{Limitations and future research recommendations}

The measurement items used for the survey in this study were adopted from the previous literature and conceptually arranged according to the dimensions. Future research may conduct a preliminary study, such as using the Delphi method, to identify more sustainable urban development indicators relevant to the topic being studied. This research introduces a new, integrated approach to measure the sustainability of cities from the residents' perspectives. Future research could use the same method on the urban experts to gain their perspectives which may add value to the outcomes. The sample of this study include a total of close to 600 residents from three cities. Future research may interrogate a greater number of respondents from each city to obtain more accurate findings regarding the individual cities. The study locations of this research are three cities in a single country. Future research could assess cities in different countries simultaneously to compare the sustainable development of cities of different nations and provide more substantial recommendations for improvement. Future research in other disciplines could also apply the IP-AHP method to study other entities' relative performance.

\section{Declarations}

Ethical approval: Ethical approval was waived by the Ethics Committee of Shanghai Jiao Tong University in view of the retrospective nature of the study.

Consent to Participate: Not applicable

Consent to Publish: Not applicable

Authors' Contributions: All authors contributed to the study. Conceptualization, material preparation, data collection and analysis were performed by Say Wah Lee and supervised by Ke Xue. The draft of the manuscript was written by Say Wah Lee and Ke Xue commented on it. Both authors read and approved the final manuscript.

Funding: Not applicable

Competing Interests: The authors declare that they have no competing interests.

Availability of Data and Materials: Not applicable

\section{References}

1. Afacan Y (2015) Resident satisfaction for sustainable urban regeneration. Munic Eng. https://doi.org/10.1680/muen.14.00046

2. Akbar M, Jinca M, Rahim J (2018) Combination of the IPA-SWOT-AHP models for the formulation of the road network of development policy (A case study in Merauke Regency, Papua Indonesia). Int J Eng Technol 18:28-34

3. Alonso J, Lamata M (2006) Consistency in the analytic hierarchy process: A new approach. Int J Uncertain Fuzziness Knowl Based Syst. https://doi.org/10.1142/S0218488506004114

4. Al-Thani $\mathrm{H}$, Koç M, Isaifan $\mathrm{R}$ (2018) A review on the direct effect of particulate atmospheric pollutionon materials and its mitigation for sustainable cities and societies. Environ Sci Pollut Res. https://doi.org/10.1007/s11356-018-2952-8

5. Andereck K, Nyaupane G (2011) Exploring the nature of tourism and quality of life perceptions among residents. J Travel Res. https://doi.org/10.1177/0047287510362918

6. Arshad Z, Robaina M, Shahbaz M, Veloso A (2017) The effects of deforestation and urbanization on sustainable growthin Asian countries. Environ Sci Pollut Res. https://doi.org/10.1007/s11356-019-07507-7

7. Asadabadi M, Chang E, Saberi M (2019) Are MCDM methods useful? A critical review of analytic hierarchy process (AHP) and analytic network process (ANP). Cogent Eng. https://doi.org/10.1080/23311916.2019.1623153

8. Bafahm A, Sun M (2018) Some conflicting results in the analytic hierarchy process. Int J Inf Technol Decis Mak. https://doi.org/10.1142/S0219622018500517

Page $8 / 14$ 
9. Bunruamkaew K, Murayam Y (2011) Site suitability evaluation for ecotourism using GIS \& AHP: A case study of Surat Thani Province, Thailand. Procedia Soc Behav Sci. https://doi.org/10.1016/j.sbspro.2011.07.024

10. Chan P, Lee M-H (2019) Developing sustainable city indicators for Cambodia through delphi processes of panel surveys. Sustain. https://doi.org/10.3390/su11113166

11. Choong J (2020) November 10) Minister: Residents of KL, Labuan, Putrajaya may hawk anything and anywhere until April. Malay Mail. https://www.malaymail.com/news/malaysia/2020/11/10/minister-residents-of-kl-labuan-putrajaya-may-hawk-anything-and-anywhereun/1921355

12. Danjaji A, Ariffin M (2017) Green infrastructure policy for sustainable urban development. Int J Environ Sustain Dev. https://doi.org/10.1504/ijesd.2017.083293

13. Department of Statistics Malaysia (2010 August 5) Population distribution and basic demographic characteristics 2010. https://www.dosm.gov.my/v1/index.php?

r=column/cthemeByCat\&cat=117\&bul_id=MDMxdHZjWTk1SjFzTzNkRXYzcVZjdz09\&menu_id=L0pheU43NWJwRWVSZkIWdzQ4TIhUUT09

14. Department of Statistics Malaysia (2020) July) Current population estimates, Malaysia, 2020. https://newss.statistics.gov.my

15. Egger S (2006) Determining a sustainable city model. Environ Model Softw. https://doi.org/10.1016/j.envsoft.2005.04.012

16. European Commission (2016) Flash Eurobarometer 419: Quality of life in European cities 2015. European Union, Auderghem

17. Federal Department of Town and Country Planning (2016) Malaysia national report for the 3rd United Nations Conference on Housing and Sustainable Urban Development (Habitat III). Ministry of Urban Wellbeing, Housing and Local Government, Putrajaya

18. Fu Y, Zhang X (2017) Trajectory of urban sustainability concepts: A 35-year bibliometric analysis. Cities. https://doi.org/10.1016/j.cities.2016.08.003

19. Gołaś J, Zarębska K, Nosek K, Szramowiat-Sala K, Marczak M (2019) Energy and environment as the foundations for sustainable development. Environ Sci Pollut Res. https://doi.org/10.1007/s11356-019-04299-8

20. Hair J, Black W, Babin B, Anderson R (2014) Multivariate data analysis, 7th edn. Pearson, Essex

21. Hoang G, Fujiwara T, Phu T, Nguyen L (2019) Sustainable solid waste management system using multi-objective decision-making model: a method for maximizing social acceptance in Hoi An city, Vietnam. Environ Sci Pollut Res. https://doi.org/10.1007/s11356-018-3498-5

22. Howley P, Scott M, Redmond D (2009) Sustainability versus liveability: an investigation of neighbourhood satisfaction. J Environ Plan Manag. https://doi.org/10.1080/09640560903083798

23. Kakar A, Khan A (2020) The impacts of economic and environmental factors on sustainable mega project development: role of community satisfaction and social media. Environ Sci Pollut Res. https://doi.org/10.1007/s11356-020-10661-y

24. Koch F, Ahmad S (2018) How to measure progress towards an inclusive, safe, resilient and sustainable city? Reflections on applying the indicators of Sustainable Development Goal 11 in Germany and India. In: Kabisch S, Koch F, Gawel E, Haase A, Knapp S, Krellenberg K (eds) Urban Transformations. Springer, Cham, pp 77-90

25. Lee SW, Xue K (2020) A model of destination loyalty: integrating destination image and sustainable tourism. Asia Pac J Tour Res. https://doi.org/10.1080/10941665.2020.1713185

26. Lirn T-C, Wu Y-CJ, Chen YJ (2012) Green performance criteria for sustainable ports in Asia. Int J Phys Distrib Logist Manag. https://doi.org/10.1108/IJPDLM-04-2012-0134

27. López C, Ruíz-Benítez R, Vargas-Machuca C (2019) On the environmental and social sustainability of technological innovations in urban bus transport: The EU case. Sustain. https://doi.org/10.3390/su11051413

28. Ma C, Li Y, Li X, Gao L (2020) Evaluation of groundwater sustainable development consideringseawater intrusion in Beihai City, China. Environ Sci Pollut Res. https://doi.org/10.1007/s11356-019-07311-3

29. Macke J, Casagrande R, Sarate J, Silva K (2018) Smart city and quality of life: Citizens' perception in a Brazilian case study. J Clean Prod. https://doi.org/10.1016/j.jclepro.2018.02.078

30. Mardani A, Jusoh A, Nor K, Khalifah Z, Zakwan N, Valipour A (2015) Multiple criteria decision-making techniques and their applications - a review of the literature from 2000 to 2014. Econ Res. https://doi.org/10.1080/1331677X.2015.1075139

31. Maryanti M, Khadijah H, Muhammad Uzair A, Megat Mohd Ghazali M (2017) The urban green space provision using the standards approach: issues and challenges of its implementation in Malaysia. WIT Trans Ecol Enviro. https://doi.org/10.2495/SDP160311

32. McNeish D (2017) Thanks Coefficient Alpha, we'll take it from here. Psychol Methods. https://doi.org/10.1037/met0000144

33. Melillo P, Pecchia L (2016) What is the appropriate sample size to run analytic hierarchy process in a survey-based research? Int Symp Anal Hierarchy Process. https://doi.org/10.13033/isahp.y2016.130

34. Mouratidis K (2017) Is compact city livable? The impact of compact versus sprawled neighbourhoods on neighbourhood satisfaction. Urban Stud. https://doi.org/10.1177/0042098017729109

Page 9/14 
35. Musa H, Yacob M, Abdullah A, Ishak M (2017) Sustainable city: Assessing the community happiness of residents in Putrajaya municipality Malaysia. Rev Eur Stud. https://doi.org/10.5539/res.v9n1p31

36. Ouria M (2019) Sustainable urban features and their relation with environmental satisfaction in commercial public space: an example of the Great Bazaar of Tabriz, Iran. Int J Urban Sustain Dev. https://doi.org/10.1080/19463138.2019.1579726

37. Peng T, Deng H (2021) Evaluating urban resource and environment carrying capacity by using an innovative indicator system based on eco-civilization-a case study of Guiyang. Environ Sci Pollut Res. https://doi.org/10.1007/s11356-020-11020-7

38. Saaty T (1980) The analytic hierarchy process: Planning, priority setting, resource allocation. McGraw-Hill, New York

39. Samat N, Ghazali S, Hasni R, Elhadary Y (2014) Urban expansion and its impact on local communities: A case study of Seberang Perai, Penang, Malaysia. Pertanika J Soc Sci Humanit 22:349-367

40. Shao J, Hu Z, Li B, Luo J, Xi J (2019) A sustainable urban design framework for the suburbanisation of coastal southeaster Australia. Environ Sci Pollut Res. https://doi.org/10.1007/s11356-019-04879-8

41. Senlier N, Yildiz R, Aktaş E (2009) A perception survey for the evaluation of urban quality of life in Kocaeli and a comparison of the life satisfaction with the European cities. Soc Indic Res. https://doi.org/10.1007/s11205-008-9361-1

42. Surendran S (2019 August 3) Why cost of living remains high. The Edge Markets. https://www.theedgemarkets.com/article/why-costliving-remains-high

43. Tabachnick B, Fidell L (2014) Using Multivariate Statistics, 6th edn. Pearson, Essex

44. Teo C, Mohd Khan N, Hj Abd Rahim F (2014) Understanding cultural heritage visitor behavior: The case of Melaka as World Heritage City. Procedia Soc Behav Sci. https://doi.org/10.1016/j.sbspro.2014.04.001

45. UN-Habitat (2017 December 28) Cities 2030, cities for all: Implementing the new urban agenda. http://wuf9.org/wpcontent/uploads/WUF9-concept-paper.pdf

46. United Nations (1987) Our common future. Oxford University Press, New York

47. United Nations (2015) Transforming our world: the 2030 agenda for sustainable development, A/RES/70/1. United Nations, New York

48. United Nations (2017) Resolution adopted by the General Assembly on 23 December 2016: New Urban Agenda, A/RES/71/256. United Nations, New York

49. United Nations (2018) 2018 revision of world urbanization prospects. https://www.un.org/development/desa/publications/2018-revisionof-world-urbanization-prospects.html

50. United Nations (2018) The Sustainable Development Goals report 2018. United Nations, New York

51. United Nations Educational, Scientific and Cultural Organization (2013) Melaka and George Town, historic cities of the Straits of Malacca. https://whc.unesco.org/en/list/1223/

52. van Kamp I, Leidelmeijer K, Marsman G, de Hollander A (2003) Urban environmental quality and human well-being: Towards a conceptual framework and demarcation of concepts; a literature study. Landsc Urban Plan. https://doi.org/10.1016/S0169-2046(02)00232-3

53. Varian H (2014) Intermediate microeconomics with calculus: A modern approach, 1st edn. W. W. Norton \& Company, New York

54. Wang M-H, Ho Y-S, Fu H-Z (2019) Global performance and development on sustainable city based on natural science and social science research: A bibliometric analysis. Sci Total Environ. https://doi.org/10.1016/j.scitotenv.2019.02.139

55. Yilmaz S, Mutlu B, Aksu A, Mutlu E, Qaid A (2020) Street design scenarios using vegetation for sustainable thermal comfort in Erzurum, Turkey. Environ Sci Pollut Res. https://doi.org/10.1007/s11356-020-10555-z

56. Youssef A, Pradhan B, Tarabees E (2011) Integrated evaluation of urban development suitability based on remote sensing and GIS techniques: contribution from the analytic hierarchy process. Arab J Geosci. https://doi.org/10.1007/s12517-009-0118-1

57. Zegras P, Poduje I, Foutz W, Ben-Joseph E, Figueroa O (2004) Indicators for sustainable urban development. In: Keiner M, Zegras C, Schmid W, Salmerón D (eds) From Understanding to Action. Springer, Dordrecht, pp 157-189

58. Zhang Y, Sun Y, Qin J (2012) Sustainable development of coal cities in Heilongjiang province based on AHP method. Int J Min Sci Technol. https://doi.org/10.1016/j.ijmst.2012.02.002

\section{Tables}

Table 1. Residents' demographic. 


\begin{tabular}{|lll|}
\hline Item & Frequency & Percent (\%) \\
Gender & & \\
Male & 289 & 48.9 \\
Age range & 302 & 51.1 \\
Below 20 years old & & \\
20-29 years old & 55 & 9.3 \\
30-39 years old & 219 & 37 \\
40-59 years old & 173 & 29.3 \\
60 years old and above & 121 & 20.5 \\
Highest education level & 23 & 3.9 \\
High school certificate & & \\
Diploma & 91 & 15.4 \\
Bachelor's degree & 105 & 17.8 \\
Master's degree & 294 & 47.9 \\
PhD & 83 & 15.9 \\
Current city of residence & 18 & 3 \\
Kuala Lumpur & & \\
Seberang Perai & 242 & 40.9 \\
Melaka City & 185 & 31.3 \\
Number of years lived in current city & & 27.8 \\
Less than 5 years & 93 & 15.7 \\
5-10 years & 88 & 14.9 \\
11-20 years & 153 & 25.9 \\
More than 20 years & 257 & 43.5 \\
\hline
\end{tabular}

Table 2. Factor analysis outcomes. 


\begin{tabular}{|c|c|c|c|}
\hline Dimension and factor & Mean & Standard deviation & Factor loading \\
\hline Economic dimension - Economy (F1) & 4.14 & 0.57 & \\
\hline Affordable cost of living & 4.28 & 0.71 & 0.806 \\
\hline Reasonable prices of goods and services & 4.33 & 0.67 & 0.875 \\
\hline Adequate number of affordable houses & 4.07 & 0.80 & 0.786 \\
\hline Diverse economy/businesses in the city & 3.91 & 0.78 & 0.564 \\
\hline Ample of employment opportunities & 4.13 & 0.80 & 0.660 \\
\hline \multicolumn{4}{|l|}{ Equal opportunities between residents ${ }^{\dagger}$} \\
\hline Social dimension & 4.35 & 0.41 & \\
\hline Wellbeing (F2) & 4.59 & 0.43 & \\
\hline Safety and security in the city & 4.72 & 0.52 & 0.697 \\
\hline Quality educational facilities and services & 4.30 & 0.65 & 0.637 \\
\hline Quality health care facilities and services & 4.57 & 0.61 & 0.855 \\
\hline Continuous access to clean water and electricity & 4.76 & 0.49 & 0.659 \\
\hline Convenience (F3) & 4.12 & 0.56 & \\
\hline Adequate retail shops and restaurants nearby & 3.95 & 0.62 & 0.801 \\
\hline Good mobility and accessibility to places in the city & 4.28 & 0.63 & 0.678 \\
\hline \multicolumn{4}{|l|}{ Good neighborhood relations and support ${ }^{\dagger}$} \\
\hline \multicolumn{4}{|l|}{ Adequate recreational and sports facilities ${ }^{\dagger}$} \\
\hline Environmental dimension & 4.21 & 0.05 & \\
\hline Conservation (F4) & 4.08 & 0.61 & \\
\hline Preservation of natural areas & 4.09 & 0.77 & 0.753 \\
\hline Maintenance of streets and buildings & 4.15 & 0.74 & 0.664 \\
\hline Adequate green spaces, e.g. parks, gardens, etc. & 4.01 & 0.81 & 0.755 \\
\hline Ambience (F5) & 4.34 & 0.61 & \\
\hline Low air pollution & 4.47 & 0.73 & 0.842 \\
\hline Low water pollution & 4.52 & 0.69 & 0.812 \\
\hline Low noise pollution & 4.20 & 0.83 & 0.814 \\
\hline Low traffic congestion issue & 4.18 & 0.78 & 0.653 \\
\hline Efficient waste management ${ }^{\dagger}$ & & & \\
\hline Not too crowded with people ${ }^{\dagger}$ & 3.64 & 0.75 & \\
\hline Cultural dimension - Culture (F6) & 3.82 & 0.91 & 0.648 \\
\hline Preservation of cultural/historical sites and buildings & 3.83 & 0.87 & 0.624 \\
\hline Strong community values and sense of belonging & 3.48 & 0.93 & 0.903 \\
\hline $\begin{array}{l}\text { Adequate cultural facilities, e.g. museums, theaters, etc. } \\
\text { Ample of cultural entertainments and activities }\end{array}$ & 3.45 & 0.96 & 0.902 \\
\hline Cultural diversity and harmony ${ }^{\dagger}$ & & & \\
\hline
\end{tabular}

${ }^{\dagger}$ Item under the dimension was removed due to low factor loading.

Table 3. Correlation analysis outcomes. 


\begin{tabular}{|c|c|c|c|c|c|c|c|c|}
\hline Factor & AVE & $\mathrm{CR}$ & 1 & 2 & 3 & 4 & 5 & 6 \\
\hline Economy & 0.557 & 0.860 & 0.747 & & & & & \\
\hline Wellbeing & 0.514 & 0.807 & $0.414^{\star \star}$ & 0.717 & & & & \\
\hline Convenience & 0.551 & 0.709 & $0.365^{\star \star}$ & $0.388 * \star$ & 0.742 & & & \\
\hline Conservation & 0.526 & 0.768 & $0.483^{\star \star}$ & $0.451^{* *}$ & $0.409 * *$ & 0.725 & & \\
\hline Ambience & 0.614 & 0.863 & $0.467 * \star$ & $0.455^{\star \star}$ & $0.314^{\star \star}$ & 0.476 ** & 0.784 & \\
\hline Culture & 0.610 & 0.858 & $0.468 * \star$ & 0.384 ** & $0.384^{* \star}$ & $0.509 * \star$ & $0.361^{* *}$ & 0.781 \\
\hline
\end{tabular}

Diagonal numbers in bold are square roots of AVE; $* \star p<0.01$.

Table 4. Performance evaluation.

\begin{tabular}{|llllllll|}
\hline City & \multicolumn{3}{l}{ Performance score } & \multicolumn{3}{c}{ Normalized weighted score } \\
\cline { 2 - 7 } & F1 & F2 & F3 & F4 & F5 & F6 & \\
Kuala Lumpur & 3.11 & 3.37 & 3.73 & 3.06 & 2.73 & 3.24 & 0.315 \\
Seberang Perai & 3.34 & 3.60 & 3.63 & 3.21 & 3.25 & 3.20 & 0.341 \\
Melaka City & 3.31 & 3.69 & 3.54 & 3.29 & 3.29 & 3.41 & 0.344 \\
Normalized weight & 0.150 & 0.389 & 0.110 & 0.080 & 0.232 & 0.039 & \\
\hline
\end{tabular}

F1 = Economy; F2 = Wellbeing; F3 = Convenience; F4 = Conservation; F5 = Ambience;

F6 $=$ Culture.

\section{Figures}




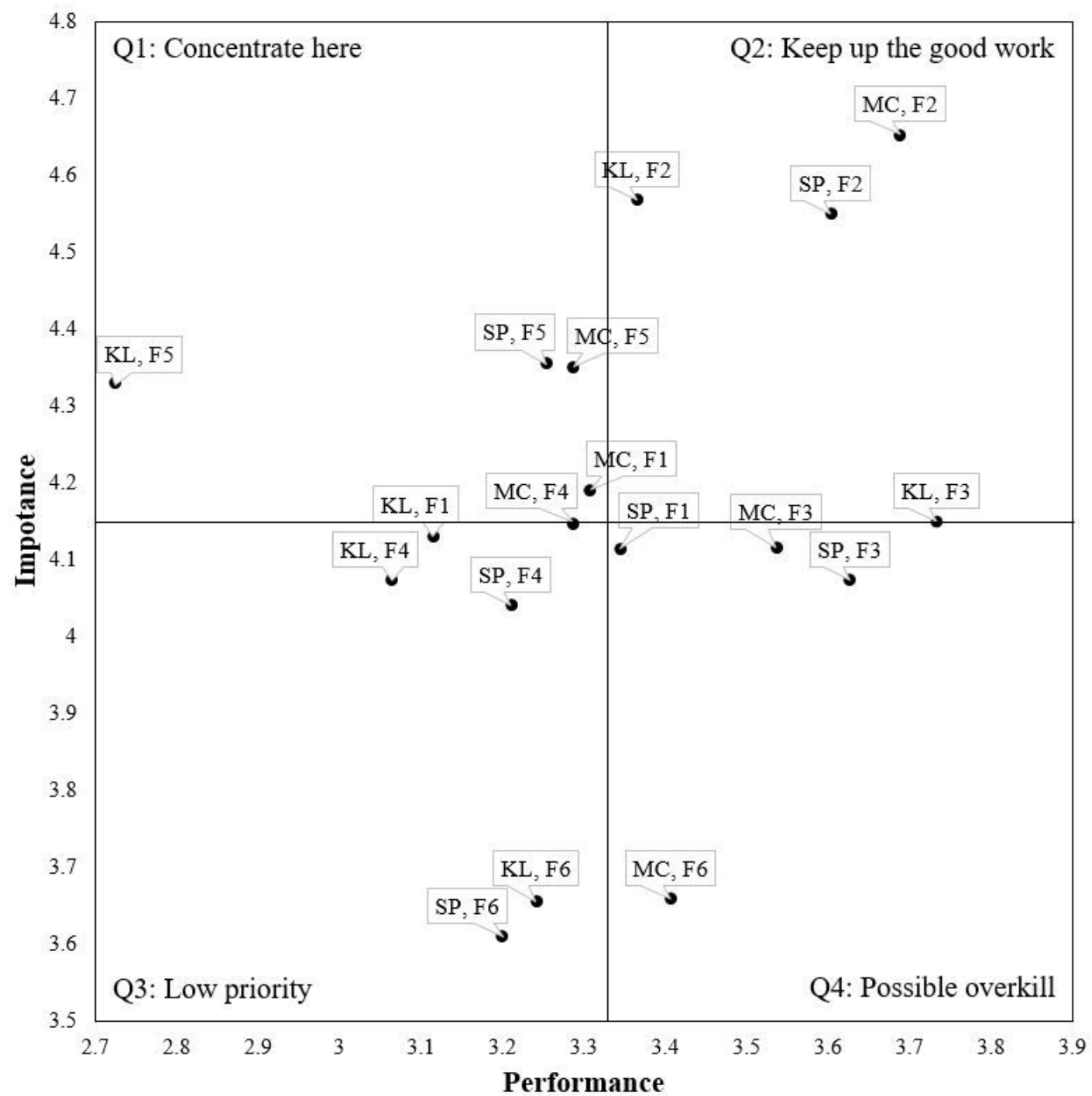

Figure 1

IPA grid. $\mathrm{KL}=$ Kuala Lumpur; $\mathrm{SP}=$ Seberang Perai; $\mathrm{MC}=$ Melaka City; F1 = Economy; F2 = Wellbeing; F3 = Convenience; F4 = Conservation; F5 = Ambience; F6 = Culture. 